\title{
COLESTASE INTRA-HEPÁTICA RECURRENTE BENIGNA: seguimento de um caso por 7 anos
}

\author{
Mônica Beatriz PAROLIN*, André Ribeiro LANGOWISKI**, \\ Sérgio Ossamu IOSHII***, Everton Marques MAGGIO ${ }^{* * * *} \mathrm{e}$ \\ Júlio C. U. COELHO*****
}

\begin{abstract}
RESUMO - A colestase intra-hepática recurrente benigna é condição rara caracterizada por episódios autolimitados e recurrentes de colestase intra-hepática, intercalados por periodos nos quais a função e histologia hepática apresentam-se normais. Embora a colestase intra-hepática recurrente benigna não se associe a dano hepático permanente, os periodos de colestase podem acompanhar-se de considerável morbidade. Relato de um caso de colestase intra-hepática recurrente benigna em adulto do sexo masculino, acompanhado por 7 anos. Durante o periodo de observação deste caso, três episódios de prurido intenso e icterícia foram documentados, tendo sido excluidas outras etiologias. A duração dos episódios variou de 50 a 90 dias. Como costuma acontecer nesta entidade, as enzimas hepáticas permaneciam normais nos intervalos entre as crises. Apesar de rara, a colestase intra-hepática recurrente benigna deve ser considerada no diagnóstico diferencial das colestases. O esclarecimento do paciente quanto à natureza benigna desta condição é importante para se evitar a iatrogênese.
\end{abstract}

DESCRITORES - Colestasia intra-hepática. Genes.

\section{INTRODUÇÃO}

A colestase intra-hepática recurrente benigna (CIRB) foi descrita inicialmente por SUMMERSKILL e WALSKE ${ }^{14,}$ 15), em 1959, quando estes autores a designaram de "icterícia obstrutiva intra-hepática recurrente benigna" para diferenciála das outras causas de colestase até então conhecidas. Tratase de entidade rara que se caracteriza por episódios autolimitados e recurrentes de icterícia e prurido de duração variável, na ausência de obstrução biliar extra-hepática. Apesar de não determinar disfunção hepática progressiva, os sintomas observados durante os episódios de colestase podem comprometer significativamente a qualidade de vida dos pacientes afetados. Embora muitos dos casos relatados tenham sido de caráter esporádico, é reconhecida a associação familial em cerca de $50 \%$ dos pacientes afetados por esta condição ${ }^{(10)}$.

O objetivo do presente artigo é relatar a evolução de um caso de CIRB ao longo de 7 anos, além de permitir comentar os principais aspectos clínicos da entidade e os avanços trazidos pelos estudos de biologia molecular em relação ao defeito genético que estaria envolvido na sua etiologia.

\footnotetext{
Serviço de Transplante Hepático e Serviço de Anatomia Patológica do Hospital de Clínicas da Universidade Federal do Paraná - UFPR, Curitiba, PR. * Hepatologista do Serviço de Transplante Hepático do Hospital de Clínicas UFPR.

** Médico Residente do Departamento de Clínica Médica - Pontifícia Universidade Católica - PUC, Curitiba, PR.

*** Professor Adjunto do Serviço de Anatomia Patológica do Hospital de Clínicas - UFPR

**** Médico Residente do Serviço de Anatomia Patológica do Hospital de Clínicas - UFPR.

***** Chefe do Serviço de Transplante Hepático do Hospital de Clínicas da UFPR

Endereço para correspondência: Mônica Beatriz Parolin - Rua Lamenha Lins, 2280 - 80220-080 - Curitiba, PR.
} 


\section{RELATO DO CASO}

Paciente masculino, branco, 35 anos, apresentou o primeiro episódio de colestase em 1992 (prurido intenso e icterícia), com duração aproximada de 50 dias, evoluindo com remissão espontânea completa dos sintomas e das anormalidades bioquímicas. Na ocasião, o paciente foi atendido em outro serviço, recebendo alta hospitalar sem esclarecimento do diagnóstico. Em dezembro de 1993, apresentou novo episódio de prurido, icterícia, colúria e acolia, sendo, então, encaminhado para o Hospital de Clínicas da Universidade Federal do Paraná-HC-UFPR, Curitiba, PR, para investigação. Ao exame físico apresentava-se eutrófico, com icterícia cutâneo-mucosa intensa, mas sem outros sinais de hepatopatia. Negava uso prévio de medicamentos ou drogas ilícitas, bem como consumo de álcool. Os exames laboratoriais eram compatíveis com quadro colestático (bilirrubina total $30 \mathrm{mg} / \mathrm{dL}$ com predomínio da fração conjugada e fosfatase alcalina 1350 UI) com aminotransferases, gamaglutamiltransferase, albumina sérica e tempo de atividade de protrombina dentro dos valores normais. Colestase extra-hepática foi afastada pelo aspecto normal das vias biliares intra e extra-hepáticas à ultra-sonografia. A pesquisa negativa de anticorpos para os vírus das hepatites A, B e C excluiu a possibilidade de hepatite colestática viral. Outras doenças, tais como doença de Wilson, deficiência de alfa-1-antitripsina, hemocromatose hereditária, hepatite autoimune e cirrose biliar primária foram afastadas pelos testes diagnósticos apropriados (ceruloplasmina $53 \mathrm{mg} / \mathrm{dL}, \mathrm{n}=$ $15-60 \mathrm{mg} / \mathrm{dL}$; alfa-1 antitripsina $373 \mathrm{mg} / \mathrm{dL}, \mathrm{n}=180-470 \mathrm{mg} / \mathrm{dL}$; índice de saturação da transferrina $50 \%$ e ferritina $151 \mathrm{ng} / \mathrm{mL}$, pesquisa negativa dos anticorpos anti-músculo liso, anti-mitocôndria, antiLKM e anti-nuclear). Considerando tratar-se de homem jovem com quadro de colestase, um dos principais diagnósticos diferenciais aventados foi colangite esclerosante primária (CEP). Para investigação dessa possibilidade, realizou-se colangiografia endoscópica retrógrada, que não identificou anormalidades nas vias biliares intra e extrahepáticas. A análise do espécime hepático obtido por biopsia percutânea foi consistente com colestase hepatocelular, não havendo evidência de injúria aos ductos biliares, que apresentavam morfologia e distribuição normais nos tratos portais. O desaparecimento das manifestações clínicas e das anormalidades bioquímicas ocorreu em 60 dias, permanecendo assintomático até outubro de 1998, quando novo surto de colestase se instalou, sendo, então, atendido no Serviço de Transplante Hepático do HC- UFPR. O quadro de colestase intrahepática, documentado pela bioquímica (bilirrubina total $8 \mathrm{mg} / \mathrm{dL}$, com predomínio da fração conjugada e fosfatase alcalina $1250 \mathrm{UI}) \mathrm{e}$ pela histologia (colestase hepatocelular) perdurou por 90 dias. Desde então, permanece assintomático e sem alteração das enzimas hepáticas. O diagnóstico de colestase intra-hepática recurrente benigna foi considerado no acompanhamento, a partir do último surto de colestase intra-hepática. Os três episódios colestáticos foram precedidos por período prodrômico de 1 a 2 semanas, durante o qual o paciente referiu mal-estar, náuseas, vômitos e diarréia. Para alívio do prurido, foi utilizada a colestiramina, com sucesso. Em setembro de 1999, realizou-se biopsia hepática percutânea, durante período em que o paciente se encontrava assintomático e sem alterações das enzimas hepáticas. A análise do tecido hepático não identificou qualquer anormalidade, reforçando a suspeita diagnóstica de colestase intrahepática recurrente benigna.

\section{DISCUSSÃO}

O diagnóstico diferencial nos quadros de colestase intra-hepática no adulto inclui condições que possam afetar o fluxo biliar, desde o nível hepatocanalicular, até os ductos biliares intra-hepáticos de pequeno calibre. De acordo com o nível em que ocorre a alteração do fluxo biliar, a colestase intra-hepática pode ser classificada em dois grandes grupos: hepatocanalicular (hepatócito e canalículo biliar) e biliar (epitélio dos ductos biliares microscópicos), conforme ilustra o Quadro $1^{(13)}$.

QUADRO 1 - Classificação da colestase intra-hepática no adulto de acordo com o local de envolvimento da árvore biliar

\author{
HEPATOCANALICULAR \\ Hepatites virais \\ Hepatite alcoólica \\ Drogas / substâncias químicas \\ Hormônios esteróides \\ Colestase da gestação \\ Colestase associada à sepse \\ Colestase associada à nutrição parenteral total \\ Colestase intra-hepática recurrente benigna
}

BILIAR

Cirrose biliar primária

Colangiopatia autoimune

Colangite esclerosante primária

Sarcoidose colestática

Ductopenia idiopática do adulto

No caso de colestase intra-hepática apresentado, alguns diagnósticos foram considerados e afastados durante a investigação. A história clínica do paciente exclui algumas das causas de colestase intra-hepática tais como: efeito tóxico de drogas, hormônios e álcool, colestase associada à sepse e à nutrição parenteral total. Hepatite colestática viral foi afastada pela pesquisa negativa dos marcadores virais e hepatopatias crônicas metabólicas e autoimunes foram descartadas pelos testes apropriados, bem como pelos achados histopatológicos. 
Diante de quadro de colestase acometendo um adulto jovem do sexo masculino e com pesquisa negativa para autoanticorpos, um diagnóstico diferencial importante se impõe - o da CEP, doença crônica caracterizada por processo inflamatório e fibrosante destrutivo que acomete as vias biliares intra- e /ou extra-hepáticas. Suas manifestações mais comuns incluem fadiga, prurido, icterícia e dor abdominal. A doença pode apresentar-se com períodos de exacerbação e remissão, sendo muito comum a associação com doença inflamatória intestinal, em especial a retocolite ulcerativa inespecífica (70\% dos casos). Alterações típicas podem ser identificadas nas vias biliares de maior calibre pelo estudo por colangiografia, tais como múltiplas áreas de estenose entremeadas por dilatações, sendo este o procedimento diagnóstico mais importante na CEP. Embora incomum, cerca de $10 \%$ dos casos de CEP podem afetar apenas ductos biliares microscópicos (pericolangite), situação em que a colangiografia não é diagnóstica ${ }^{(1)}$. No presente caso, o aspecto normal das vias biliares de maior calibre à colangiografia, a histologia hepática mostrando apenas colestase hepatocelular sem evidência de injúria alguma aos ductos biliares nos tratos portais, a ausência de doença inflamatória intestinal associada e a normalização completa das alterações clínicas e bioquímicas espontaneamente, tornam improvável o diagnóstico de CEP. Outra entidade também excluída foi a ductopenia idiopática do adulto, não só pela ausência de alterações nos ductos biliares nos espécimes de biopsia hepática analisados, mas também pela remissão espontânea das alterações clínicas e bioquímicas ${ }^{(13)}$.

As alterações clínicas e de exames complementares que sugeriram o diagnóstico no presente caso, foram o caráter recurrente dos episódios de colestase intra-hepática sem fator precipitante evidente, resolução espontânea e completa das manifestações clínicas e das alterações bioquímicas, quadro histológico de colestase hepatocelular sem envolvimento dos ductos biliares e ausência de anormalidades que sugerissem outras formas de hepatopatia, normalização das alterações histopatológicas acompanhando a remissão do quadro clínico e laboratorial de colestase, aspecto normal das vias biliares à colangiografia.

O caso relatado preenche os critérios diagnósticos para a CIRB propostos por TYGSTRUP ${ }^{(17)}$, em 1969: (1) pelo menos dois episódios de icterícia e prurido separados por períodos assintomáticos com duração de vários meses a anos; (2) alterações bioquímicas consistentes com colestase; (3) demonstração de colestase centrilobular em espécime hepático; (4) vias biliares intra e extra-hepáticas normais à colangiografia; (5) ausência de outras causas conhecidas de colestase. Aspecto interessante a ser comentado é que, embora o diagnóstico possa ser suspeitado após a resolução do primeiro episódio de colestase, o diagnóstico definitivo de CIRB não pode ser feito antes que um segundo ou terceiro episódio de colestase sintomática se desenvolva e se resolva espontaneamente. Tal peculiaridade justifica o intervalo decorrido entre o primeiro episódio de colestase apresentado neste caso, e a época em que o caso foi diagnosticado como sendo CIRB.

A CIRB afeta mais freqüentemente indivíduos do sexo masculino e suas manifestações cardinais são o prurido e a icterícia. $O$ episódio inicial ocorre freqüentemente entre 10 e 30 anos de idade. A duração e o número de ataques variam amplamente entre os pacientes ${ }^{(2,3,10,11)}$. Durante as crises, outros sintomas, tais como desconforto no quadrante superior direito do abdome, mal-estar, irritabilidade, náuseas, vômitos e anorexia podem estar presentes. Menos freqüentemente, febre, artralgias, cefaléia e urticária podem ser referidos ${ }^{(10)}$. Recentemente, CHATILA et al. ${ }^{(6)}$ relataram a ocorrência de tosse intratável e anormalidades das provas de função pulmonar no decurso de um episódio de colestase em uma portadora de CIRB. Tais anormalidades desapareceram espontaneamente com o término do quadro de colestase. Os autores especulam que substâncias circulantes que se acumulam na vigência de colestase ou um reflexo neurogênico, possivelmente pela estimulação vagal a nível hepático, poderiam estar envolvidos na gênese da tosse. Episódios de colestase com duração prolongada podem cursar com perda de peso, atribuída à anorexia e à esteatorréia. Manifestações hemorrágicas e alterações da coagulação podem surgir pela deficiência na absorção da vitamina K. À semelhança do relatado no presente caso, o exame físico não revela outra anormalidade, com exceção da icterícia. Manifestações do tipo influenza ou gastroenterite costumam preceder os surtos de colestase, o que foi confirmado no caso relatado ${ }^{(10)}$.

Um aspecto peculiar das anormalidades encontradas nas enzimas hepáticas na CIRB é que a gamaglutamiltransferase, que quase invariavelmente se eleva nos quadros de colestase, apresenta-se normal ou discretamente alterada nesta entidade ${ }^{(9,10)}$. Durante os ataques de CIRB, há aumento na concentração sérica de ácidos biliares. Tal anormalidade resulta de defeito na secreção de ácidos biliares no plano canalicular $^{(10)}$.

Predisposição familial para a CIRB está bem descrita e estudo em várias gerações de uma família afetada pela CIRB concluiu que esta doença tem padrão de herança autossômico recessivo ${ }^{(7)}$. Entretanto, formas esporádicas, como a que este caso apresenta, têm sido relatadas ${ }^{(10)}$. Recentemente, duas mutações pontuais no braço longo do cromossoma 18 na posição 18q21-q22 foram identificadas em portadores de $\mathrm{CIRB}^{(5,8,12)}$. O gene designado de FIC-1 (familial intrahepatic cholestasis), codifica uma ATPase tipo $\mathrm{P}$, que se assemelha às proteínas envolvidas no posicionamento de aminofosfolipídios na membrana celular, evento fundamental para assegurar a fluidez desta estrutura $^{(4,16)}$. Postula-se que um defeito na função desta ATPase, ao determinar um posicionamento inadequado dos aminofosfolipídios na membrana celular, poderia afetar a função de várias proteínas transportadoras, altamente suscetíveis a alterações na fluidez da membrana $^{(12)}$. 
Outra condição colestática — a colestase intra-hepática familial progressiva ou doença de Byler - foi associada a cinco mutações pontuais no gene $F I C-1^{(3,5,8)}$. Diferente da CIRB, a doença de Byler tem curso progressivo, evoluindo para insuficiência hepática grave. Baseados na diferença no número de mutações identificadas no gene FIC-1 nestas duas condições, alguns autores especulam que o produto protéico do FIC-1 na CIRB poderia ser disfuncional ou mais suscetível a outras formas de injúria, o que explicaria a natureza recurrente da doença. Ao contrário, na doença de Byler, esta proteína seria totalmente desprovida de atividade, o que justificaria o curso inexoravelmente progressivo desta doença ${ }^{(10)}$. Outra hipótese é que a proteína codificada pelo $F I C-1$ represente algum outro tipo de proteína transportadora, possivelmente envolvida na transporte de cátions ou ácidos biliares ${ }^{(12)}$.

Não se dispõe, até momento, de terapêutica específica que possa prevenir ou limitar a duração dos episódios de colestase. Medidas terapêuticas, tais como o uso de rifampicina, fenobarbital, ácido ursodeoxicólico, S-adenosilmetionina e plasmaferese têm sido empregadas para aliviar o prurido ${ }^{(10)}$. Entretanto, os autores são unânimes ao afirmar que o pequeno número de pacientes tratados e a grande variabilidade na duração dos episódios de colestase e períodos assintomáticos dificultam a avaliação do real benefício de tais medidas. É provável que o tratamento da CIRB permaneça empírico até que se obtenha melhor conhecimento da entidade, do ponto de vista da biologia molecular e do estudo genético.

Parolin MB, Langowiski AR, Ioshii SO, Maggio EM, Coelho JCU. Benign recurrent intrahepatic cholestasis: a seven-year follow-up report. Arq Gastroenterol 2000;37(4):231-234.

ABSTRACT - Benign recurrent intrahepatic cholestasis is a rare autosomal recessive disorder characterized by repeated episodes of intense pruritus and jaundice. Patients are completely asymptomatic for months to years between symptomatic periods. We report a case of a patient with a 7-year history of benign recurrent intrahepatic cholestasis. During the follow-up period the patient has suffered three attacks of cholestasis, confirmed by biochemical tests and histological exam. Liver enzimes were normal between the cholestasis episodes. Despite multiple attacks of cholestasis, no permanent liver damage has occurred. Although the diagnosis of benign recurrent intrahepatic cholestasis is rare, it should be included in the evaluation of a patient with cholestasis. The patients should be reassured of the benign course of this disorder.

HEADINGS - Cholestasis, intrahepatic. Genes.

\section{REFERÊNCIAS BIBLIOGRÁFICAS}

1. Angulo P, Lindor KD. Primary biliary cirrhosis and primary sclerosing cholangitis. Clin Liv Dis 1999;3:529-70.

2. Brenard R, Geubel AP, Benhamou JP. Benign recurrent intrahepatic cholestasis. J Clin Gastroenterol 1989;11:546-51.

3. Bijleveld CM, Vonk RJ, Kuipers F, Havinga R, Fernandes J. Benign recurrent intrahepatic cholestasis: a long-term follow-up study of two patients. Hepatology 1989;9:532-7.

4. Bull LN, van Eijk MJT, Pawlikowska L, De Young JA, Juijn JA, Liao M, Klomp LW, Lomri N, Berger R. A gene encoding a P-type ATPase mutated in two forms of hereditary cholestasis. Nat Genet 1998;18:219-24.

5. Carlton VEH, Knisely AS, Freimer NB. Mapping of a locus for progressive familial intrahepatic cholestasis (Byler's disease) to 18q21-q22, the benign recurrent intrahepatic cholestasis region. Hum Mol Genet 1995;4:1049-53.

6. Chatila R, Bergasa NV, Lagarde S, West AB. Intractable cough and abnormal pulmonary function in benign recurrent intrahepatic cholestasis. Am J Gastroenterol 1996;91:2215-9.

7. De Koning TJ, Sandekujil LA, De Schryver JE, Hennekam EA, Beemer FA, Houwen RHJ. Autosomal-recessive inheritance of benign recurrent intrahepatic cholestasis. Am J Med Genet 1995;57:479-82.

8. Houwen RHJ, Baharloos, Blankenship K, Raeymaekers P, Juyn J, Sandkuijl LA, Freimer NB. Genome screening for shared segments: mapping a gene for benign recurrent intrahepatic cholestasis. Nat Genet 1994;8:380-6.
9. Lachaux A, Loras-Duclaux I, Bouvier R, Dumontet C, Hermire M. Benign recurrent cholestasis with normal gamma-glutamyl-transpeptidase activity. J Pediatr 1992;121:78-80.

10. Luketic VA, Shiffman ML. Benign recurrent intrahepatic cholestasis. Clin Liv Dis 1999;3:509-28.

11. Nakamuta M, Sakamoto S, Miyata Y, Sato M, Nawata H. Benign recurrent intrahepatic cholestasis: a long-term follow-up. Hepatogastroenterology 1994;41:287-9.

12. Oude Elferink RPJ, Van Berge Henegouwen GP. Cracking the genetic code for benign recurrent and progressive familial intrahepatic cholestasis. J Hepatol 1998;29:317-20.

13. Sherlock S. Overview of chronic cholestatic conditions in adults: terminology and definitions. Clin Liv Dis 1998;2:217-33.

14. Summerskill WHJ, Walshe JM. Benign recurrent intrahepatic "obstrutive" jaundice. Lancet 1959;2:686-90.

15. Summerskill WHJ. The syndrome of benign recurrent cholestasis. Am J Med 1965;38:298-305.

16. Tang X, Halleck MS, Schlegel RA, Wiiliamson P. A subfamily of P-type ATPases with aminophospholipid transporting activity. Science 1996;272:1495-7.

17. Tygstrup N, Jensen B. Intermittent intrahepatic cholestasis of unknown etiology in five young males from the Faroe Islands. Acta Med Scand 1969;185:523-30.

Recebido para publicação em 3/11/1999. Aprovado para publicação em 9/6/2000. 